\title{
Damping Computation of Nose Wheel Steering Shimmy of Aircraft
}

\author{
Jiangtao Chen ${ }^{1},{ }^{*}$ Rui Liu ${ }^{1}$ \\ ${ }^{1}$ China Aviation Industry General Aircraft Institute Co. Ltd., Zhuhai, Guangdong, China \\ ${ }^{*}$ Corresponding Author:Jiangtao Chen
}

Keywords:Damping Computation, Damper, Nose Wheel Steering, Anti-shimmy

\begin{abstract}
Nose wheel steering control system is the kernel of the ground maneuvers, and has its own notable functions and features. After the introduction of Principle and State of nose wheel steering system, this paper computes the damping of aircraft's shimmy and gives the simulation analysis of damping functions and damping features of aircraft's shimmy to give some references for the relevant researchers.
\end{abstract}

\section{Introduction}

Electro hydraulic servo control system is adopted in the nose wheel steering system, which is the direction control of the ground sliding stage and the elimination of the disturbance of the front wheel.

Working Principle.Nose wheel steering system main accessories including: turning the hand wheel, cockpit lift switch, rudder pedals. Ground lift switch, which in turn control valve assembly, turning actuator. Turn the hand wheel and rudder pedals for aircraft steering input. Cockpit lift switch for emergency cut off steering system, front wheel into the free steering mode, with the continuous improvement of the redundant system design and control system of electronic components reliability to lift the switch has been fully meets the requirements for the security of the system. Turning control unit mainly to achieve the input of each sensor, and according to the preparation of the control rate of the turn of the calculation analysis, the steering command input turn hydraulic valve components, through the implementation of the hydraulic turn.Control system is divided into the turning state hand wheel and pedal control. Hand wheel is mainly used for low speed control under the condition of large angle turning direction, and pedal manipulation is used for aircraft ground high speed skating in the direction of movement of the small angle adjustment. The conversion of the system operating state is accomplished by the controller on the driver's control panel. When the front wheel turning conditions are satisfied, the rotation angle of the input of the turn signal, and a system of feedback signal is transmitted to the controller, by the controller to determine the input signal and feedback signal between difference control servo valves of the valve opening to obtain takes the steering angle and velocity. When the current wheel angle reaches the corresponding angle of the input signal, the signal output by the controller is zero. The nose wheel is stopped at the corresponding position, and the servo control of the front wheel turning is realized.

Working State.Therefore, the system has two kinds of working states, which are turning and damping.Correspondingly, the hydraulic system of the hydraulic system has two corresponding working loops, which is a turning loop of the front wheel turning system and a reduced swing circuit. In turn, by the driver input control signal makes the selected valve opens to the left, and activates the shunt valve, allowing the system to in turn ready state, at this time two steering actuator cylinder working path shunting isolation valve. The driver can input the turning signal to 
the servo valve through the controller, the servo valve outputs the corresponding pressure according to the obtained turning instructions, and drives the two steering wheels to move, thereby realizing the front wheel deflection. The current round does not need to turn or the system electrical part of the fault, the front wheel steering system is in a state of decline, the two cylinders are connected to each other. At this time, if the front landing gear rack due to impact and other reasons have shimmy for dynamic barrel of oil can be through the reduction of the pendulum and diverter valves from a cylinder flows to another as actuating cylinder, shimmy damping effect of valve system pendulum vibration energy conversion into heat dissipation off, so as to achieve reduction pendulum effect shimmy loop, in addition to shimmy valve outside, also set up a safety valve and accumulator. Energy storage device is used to prevent the impact of unilateral for cylinder temporary vacuum or pressure when cavitation.

\section{Damping Computation ofAircraft's Shimmy}

The energy loss due to the significant change in the liquid and the vortex, coupled with the viscous friction, is generally expressed as:

$$
\Delta p=\varsigma \frac{1}{2} \rho V^{2}
$$

In the formulation (1), $\Delta p$ is the change value of pressure; $\mathrm{V}$ is the average flow rate; $\rho$ is the density of oil; $\varsigma$ is the local flow resistance coefficient.

After calculating the pressure change, the total pressure loss can be obtained, which is assumed to be $\Delta p$. At the same time, assuming that the piston cross-sectional area is, the rocker arm length is $\mathrm{R}$, we can calculate the damping torque.

$$
M=\Delta p A_{H} R(2)
$$

This paper studies the piston type damper. If we do not consider the piston and the casing gap oil leakage, reducing the swing device for pipeline in series form, in series in the pipeline, the segment the same flow, the pipeline pressure loss is the sum of all segments of the pressure loss. The formula for calculating the damping coefficient is:

$$
h=\frac{\varsigma \gamma A_{H} R^{3}}{2 g} \text { (3) }
$$

When the piston and the shell are considered to have a clearance between the piston and the cylinder, they are filled with a damper line to form a parallel line. In parallel pipelines, the pressure loss of each branch is the same, and the sum of the flow rate is equal to the total flow rate.We use the method to calculate the value. The damping torque of the damper is:

$$
M=K \gamma(A R)^{3} \phi^{2}(4)
$$

The minimum equivalent linear damping coefficient:

$$
h_{\min }=\frac{8}{\pi} \sqrt{\frac{2}{3} h_{0} M_{0}}(5)
$$


The device can provide the reduction of pendulum damper coefficient which has been calculated. Whether it can meet the large civil aircraft during taxiing shimmy requirements, we need a dynamic model simulation to verify.

\section{Simulation Analysis of Aircraft's Shimmy}

Simulation Analysis of Damping Functions.We switch the visible analysis systemto shimmy, and the actuating cylinder piston rod applied external impact load, the system of shimmy function validation and external load in $0.5 \mathrm{~s}$ quickly from 0 increases to $100 \mathrm{kN}$, keep 0.3 s quickly reduced to 0 , the approximate simulation of aircraft on the ground taxiing of tire from the ground impact load due to the double actuating cylinder type front wheel turning mechanism, two cylinders are symmetrically distributed in the shimmy state stress also basic symmetric. When after the disappearance of the load, the piston acceleration after slight oscillations in reducing swing valve hydraulic damping effect decreases rapidly until reaching to 0 simulation results are basically consistent with the actual situation, in under the action of hydraulic impact generated by the piston acceleration in the acceptable range. The curve of acceleration and time can be expressed by Figure

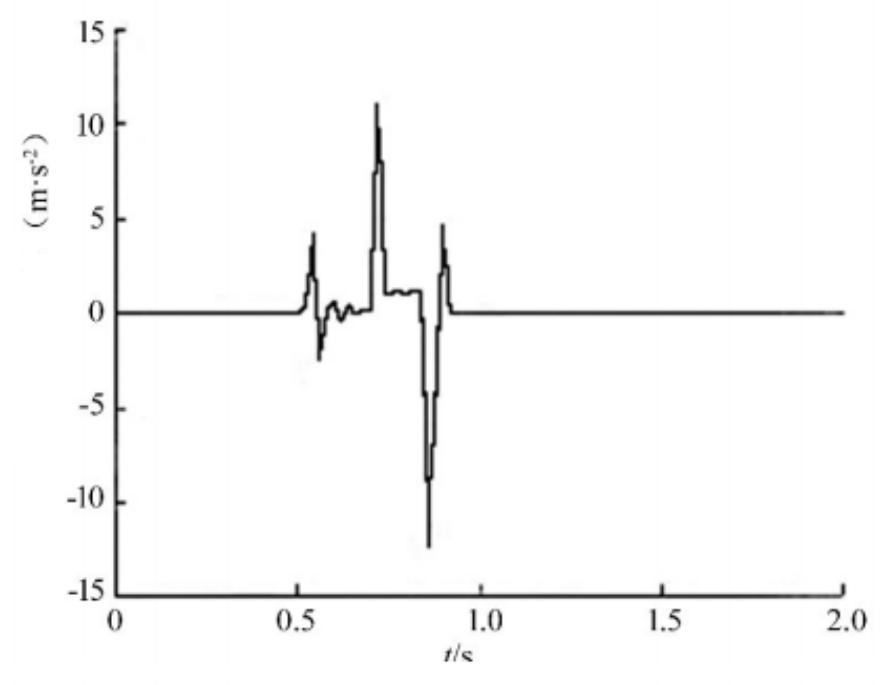

Figure 1.Relationship of acceleration and time in damping state

Simulation Analysis of Damping Features. In order to simulate the shimmy process controlled by hydraulic system, add the angle of drive in the dynamic model, simulation of front wheel shimmy at the same time by adding the input and output control node to set the data communication port. The corresponding size of Figure 2 shows the simulation results. The Figure 2, 3, 4 and 5 are the downstream oil pressure of backfill valve 1, the flow rate of backfill valve 1, the downstream oil pressure of backfill valve 2 and the flow rate of backfill valve 2. When the pressure is less than 12bar, the oil valve backfill 1 downstream will open. The accumulator to the system to add pressure; fill valve 2 downstream oil pressure is always greater than 12bar, so the fill valve 2 has been in a closed state. Energy storage releaser flow equals two backfill flow valve and according to shimmy circuit working principle, energy storage device and backfill valve in the system of the role is in order to prevent the pressure in the system is too low and the cavitation by the simulation analysis, we can see that when the system pressure is lower than the accumulator set pressure, energy storage device. It is the supplementary pressure, which can maintain system pressure and avoid the occurrence of cavitation. 

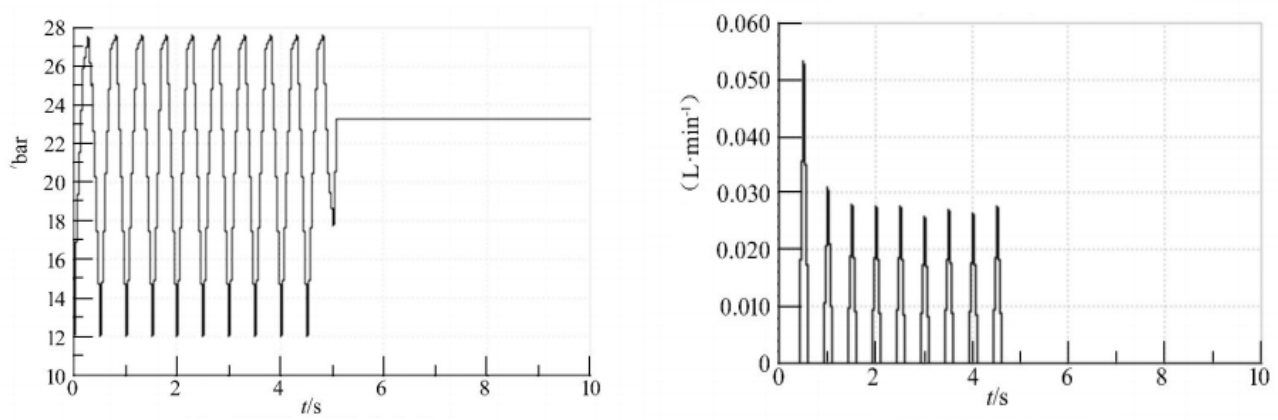

Figure 2.Downstream oil pressure of valve 1 Figure 3.Flow rate of valve 1

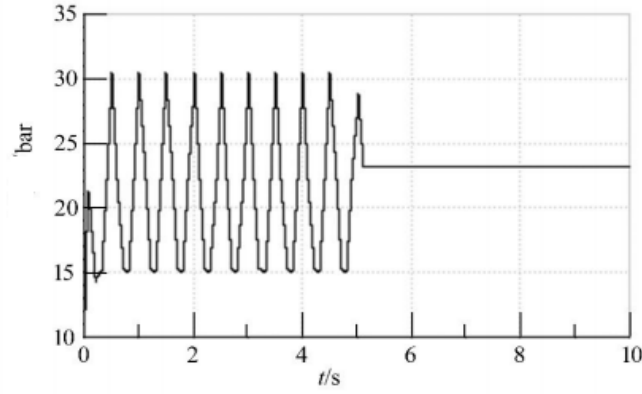

Figure 4.Downstream oil pressure of valve 2

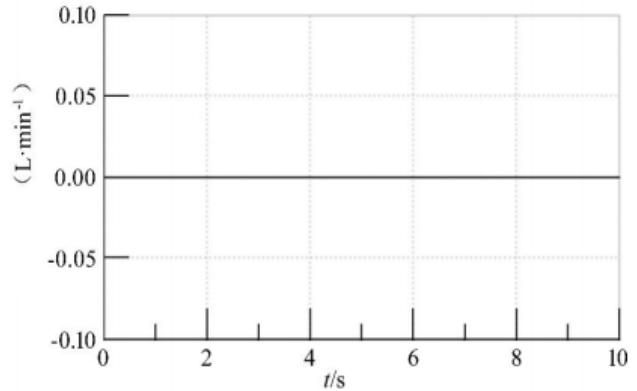

Figure 5.Flow rate of valve 2

\section{Conclusion}

In this paper, we calculate the damping of the shimmy of the nose wheel steering system and make the shimmy performance simulation analysis. From the simulation, we can know that the damping force will increase with the increase of swing frequency and swing angle but will decrease with the increase of the diameter of the damping hole.

\section{References}

[1]Zhang Dandan, Zhang Ming, Machine Design and Manufacturing Engineering, Vol. 44 (2015) No 2,p.21-26

[2]Nie Qing, Nie Hong, Zhang Ming, JiMeishan, Mechanical Science and Technology for Aerospace Engineering, Vol. 32 (2013) No 9,p.1291-1297

[3] Mu Zhitao, XiongYuping, Machine Tool \& Hydraulics, Vol. 30(2002) No 1,p.130-131

[4] Xia Yubing, ZhongKelin, Jiang Yimin, Science \& Technology Information, Vol. 8(2010) No 32,p.2-3

作者：陈江涛，刘瑞

单位: 中航通飞研究院有限公司

邮寄地址：广东省珠海市金湾区航空产业园中航通飞研究院有限公司 陈江涛（收） 
邮编: 519040

联系电话: 18926916712 